\title{
Recurrent Childhood Malignant Solid Neoplasm
}

National Cancer Institute

\section{Source}

National Cancer Institute. Recurrent Childhood Malignant Solid Neoplasm. NCI

Thesaurus. Code C148026.

The reemergence of a childhood malignant solid neoplasm after a period of remission. 